\title{
Vol. 66, No. 27
}

In "Racial and Geographic Differences in BreastfeedingUnited States, 2011-2015," on page 723, in the first paragraph, the fifth sentence should have read, "Among the 34 states (including the District of Columbia [DC]) with sufficient sample size ( $\geq 50$ per group), initiation rates were significantly $(\mathrm{p}<0.05)$ lower among black infants than white infants in 22 states; in 14 of these states (primarily in the South and Midwest), the difference was at least 15 percentage points."

On page 727 , under "What is added by this report?" the second sentence should read, "Breastfeeding initiation rates were significantly lower among black infants in $\mathbf{2 2}$ states; in 14 of these states, the difference was at least 15 percentage points." 